\title{
IDENTIFYING CARBON SINKS WITH THE USE OF HYPERSPECTRAL IMAGES: A POTENTIAL TOOL FOR LANDSCAPE PLANNING
}

\author{
R. Amaral ${ }^{1}$, G. M.M. Baptista ${ }^{2}$, M. C. L. Bezerra ${ }^{3}, *$ \\ ${ }^{1}$ Architecture and Urbanism Faculty, University of Brasília, 70842-970, Brasília, Brazil - amaral.arqbr@ gmail.com \\ ${ }^{2}$ Institute of Geoscience, University of Brasília, 70842-970, Brasília, Brazil - gmbaptista@ gmail.com \\ ${ }^{3}$ Architecture and Urbanism Faculty, University of Brasília, 70842-970, Brasília, Brazil - mdclbezerra@ gmail.com
}

KEY WORDS: Remote Sensing, Hyperion, Hyperspectral images, Ecosystem Services, Landscape Planning, Carbon Sequestration, Carbon Sinks.

\begin{abstract}
:
There is a lack of assertive carbon sink identification techniques and guidelines to underpin landscape planning based on the promotion and protection of support ecosystem services, as well as other categories, needed for human well-being (regulation, provision and culture). Considering this, the present article aims to identify carbon sinks in stretches of the territorial landscape of Distrito Federal, by the use of remote sensing tools. To this end, it was applied the hyperspectral index $\mathrm{ICO}_{2}$ in a stretch of Distrito Federal's landscape, seeking variations of $\mathrm{CO}_{2}$ in the atmospheric air column of areas with carbon sink action. Then, it was applied an index - $\mathrm{CO}_{2}$ flux - in the same stretch, in a different approach: variations in carbon sequestration in vegetation performance (photosynthetic efficacy) in areas with carbon sink behavior. In sequence, the correlation between the indexes above was verified for the validation of the carbon sinks that have been found by both methods.
\end{abstract}

\section{INTRODUCTION}

Human actions over natural ecosystems have endangered human well-being, besides threatening other species. On the other side, the fullness of the ecosystems ensures services for providing access to water, clean air, food, as well the integrity of the building environment, preventing impacts as floods, landslides, droughts, loss of cultures and diseases.

The support ecosystem services (primary production, nutrients cycle and soil formation) are prerequisites for the other categories attached to the human welfare: regulation, provision and culture. But the traditional model of territorial occupation is not premised on the supply of ecosystem services, specially support services, demanding studies to integrate these knowledge fields.

Supporting ecosystem services are intertwined with the presence of vegetation in the territory, especially the arboreal type, and its performance in carbon sequestration, which, when effective, configure carbon sinks.

To this end, the identification of carbon sinks and their different performances in carbon sequestration would provide subsidies to integrate aspects about the dynamics of the support ecosystem services to the landscape planning in the territory, creating a favorable basis for the implementation of other categories of ecosystem services.

However, there is a lack of assertive carbon sink identification techniques and guidelines to underpin landscape planning based on the promotion and protection of support ecosystem services as well as the others categories, needed for human welfare (regulation, provision and culture).

Thus, an opportunity arises to integrate disciplinary fields linked to remote sensing with the analysis of landscape performances in the provision of ecosystem services according to the Millennium Ecosystem Assessment Board (MEA, 2005); The identification of carbon sinks in the territory can offer evidences to instrumentalize landscape interventions through vegetation management, assertively directed to the provision and promotion of ecosystem support services, probably fostering the other ecosystem services categories.

There is a plethora of positive impacts for the human welfare, by increasing ecosystem services through the territory: food supply, fresh water, timber production (provision services); natural drainage, climate regulation, polinization, erosion control (regulation services) and leisure, spiritual values, tourism and sense of belonging (cultural services), for example. So the use of remote sensing tools for the development of techniques and guidelines to identify carbon sinks in the landscape not only has the potential to ensure the promotion of ecosystem services along the territory but also to democratize the access to benefits such as the ones listed above.

Among the latest remote sensing tools with the potential to identify carbon sinks, figures the hyperspectral sensors. They allow a detailed analysis of the properties of targets or materials, representing a solid approach to remote sensing techniques. Hyperspectral sensors, having high spectral dimensions (220 bands), provide a diversity of information on structure, biochemical and physiological properties, nutrient concentrations, pigment, FPAR and utilization of light efficiency. In Brazil, the applicability of hyperspectral images from Hyperion sensors has gained gradual emphasis. Many authors use sensor images to analyze various features, including those related to vegetation and $\mathrm{CO}_{2}$ flow (Galvão et al., 2005; Schramm; Vibrans, 2007, Silva and Baptista, 2015; Baptista, 2019).

Taking the above facts into consideration, the present article aims to identify carbon sinks in stretches of the territorial landscape of Distrito Federal, by the use of remote sensing tools.

For this purpose, it was applied the hyperspectral index $\mathrm{ICO}_{2}$ in a stretch of Distrito Federal's landscape, seeking variations of $\mathrm{CO}_{2}$ in the atmospheric air column of areas with carbon sink action.

Then, it was applied an index - $\mathrm{CO}_{2}$ flux - in the same stretch, in a different approach: variations in carbon sequestration in

* Corresponding author 
vegetation performance (photosynthetic efficacy) in areas with carbon sink behavior. Afterwards, the correlation between the indexes above was verified for the validation of the carbon sinks that had been found by both methods.

\section{MATERIALS AND METHODS}

\subsection{Case study}

The case study is configured in a stretch of the territorial landscape of Distrito Federal, a federative unit of Brazil, which houses its capital, Brasília. The Distrito Federal is located in the Midwest region of the country, being the smallest Brazilian federative unit and the only one without municipalities (image 1). It is divided into 31 administrative regions, totalling an area of $5,779,997 \mathrm{~km}^{2}$ (IBGE, 2019).

Throughout Distrito Federal is a plethora of types of land use and occupation, intertwined with a range of native and exogenous vegetation, which could present a significant variation in the provision of support ecosystem services, with different carbon sink performances.

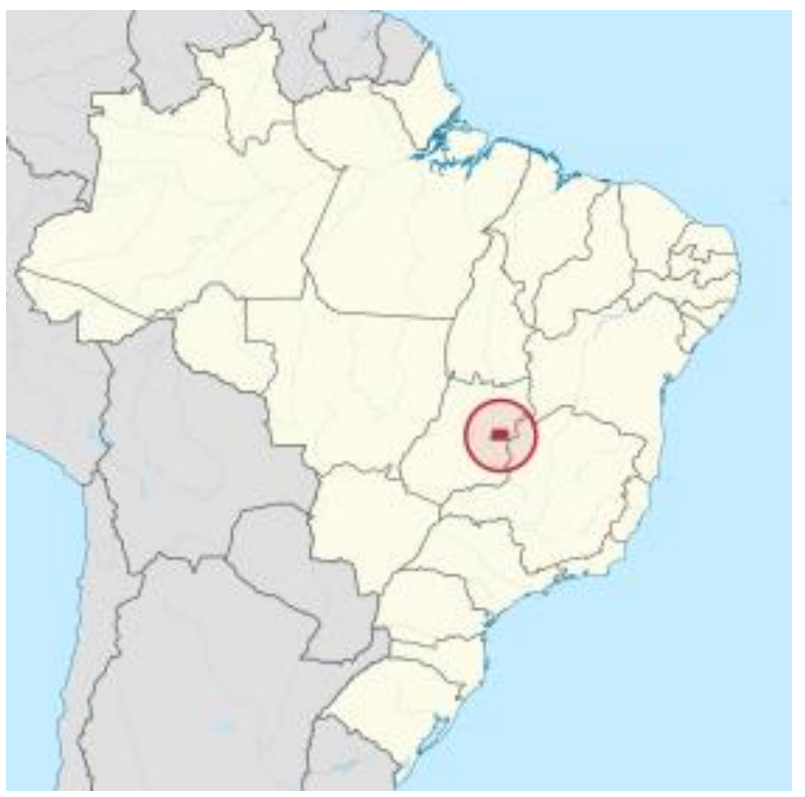

Image 1. Distrito Federal, Brazil

Thus, it was selected the hyperion scene E01H2210172014119110KF_L1GST, from 2014, October: a period in the end of the dry season in the Midwest region - no precipitations - and without extreme climate events as La Niña or El Niño. In this scene, according to image 2, a transect was traced, along which the dynamics related to the presence and absorption of $\mathrm{CO}_{2}$ through the landscape to be investigated.

Hyperion is a hyperspectral sensor installed in an EO1 satellite, with visible and infrared imagery, consisting of 220 bands that cover the reflected spectrum with 16 bits of radiometric resolution. It has 30 meters of spatial resolution and a $10 \mathrm{~nm}$ bandwidth (BAPTISTA; 2019). In hyperspectral remote sensing, for each pixel of the image there is a measured spectrum of electromagnetic energy that reaches the sensor. Since each pixel has a reflectance or radiance value for each of 220 bands, it is possible to obtain a continuous spectrum, which can be used to derive a large amount of information about the territory, based on the spectral signature of the targets and the relations between matter and energy (BAPTISTA, 2004; 2019).

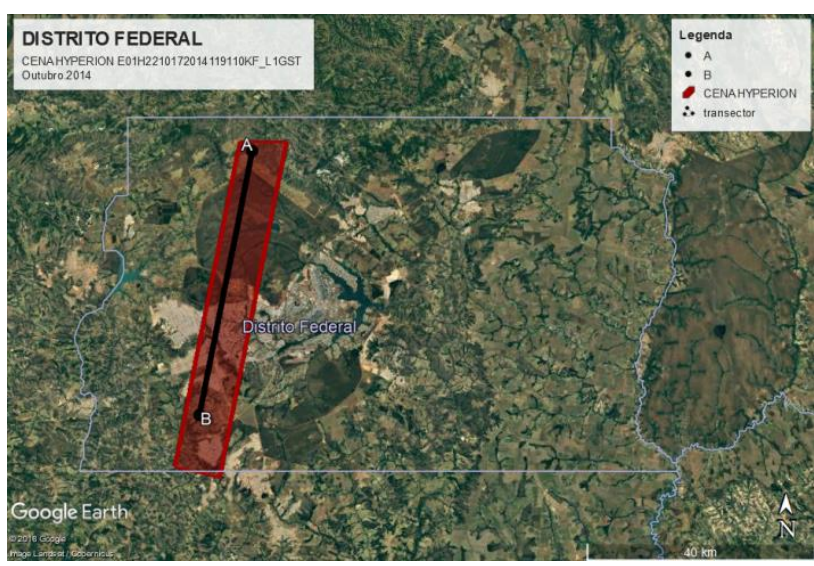

Image 2. HYPERION scene

E01H2210172014119110KF_L1GST and study transect A-B

1.2 Determining $\mathrm{CO}_{2}$ in the atmospheric air column by spectral indexes

According to Gao et al. (1993), atmospheric carbon dioxide $\left(\mathrm{CO}_{2}\right)$, produces features perceivable by hyperspectral sensors in the range of 0.4 to $2.5 \mu \mathrm{m}$, as shown in image 3 .

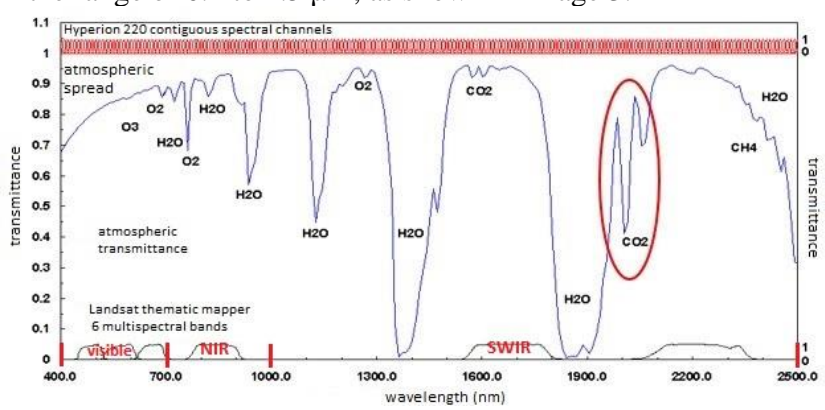

Image 3. Comparison between gas transmittance spectra, highlighting atmospheric carbon dioxide. Adapted from Green (2001)

For determining the $\mathrm{CO}_{2}$ content in the atmospheric air a spectral index, called $\mathrm{ICO}_{2}$, was proposed, establishing the intensity of the gas absorption feature centred in $2.0 \mu \mathrm{m}$, by subtracting the maximum point from the minimum point of radiance, located at 2,037 and $2,007 \mu \mathrm{m}$, respectively. $\mathrm{ICO}_{2}$ visualization is possible in image 4

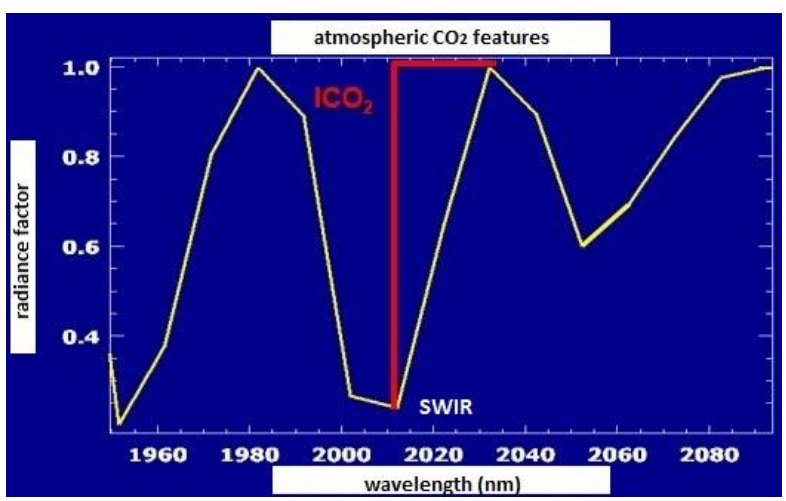


Image 4. Intensity of the atmospheric $\mathrm{CO}_{2}$ spectral feature obtained in a HYPERION scene, related to the $\mathrm{ICO}_{2}$ index.

\subsection{Determining the $\mathrm{CO}_{2}$ flux by spectral indexes}

The $\mathrm{CO}_{2}$ flux index measures the process of carbon sequestration by vegetation. For its determination, the integration of NDVI (Vegetation Index of Normalized Differences) and sPRI (Rescaled Photochemical Reflection Index for positive values) are necessary. NDVI uses the red and infrared bands in the sum-normalized difference process, which aims to display a percentage relationship between one band and another. This arithmetic operation allows a clear distinction of vegetation areas due to the absorption ratio in the red range and the peak reflectivity in the near infrared range. The NDVI index (Equation 1) consists of the reflectance difference between red absorption $(0.66 \mu \mathrm{m})$ and the increase in albedo that occurs in vegetation spectra after the beginning of infrared $(0.8 \mu \mathrm{m})$ (RAHMAN et al ., 2000; Silva and Baptista, 2015).

$$
N D V I=\frac{R_{0,800}-R_{0,660}}{R_{0,800}+R_{0,660}}
$$

Where: $\mathrm{R}$ is the reflectance value at each wavelength, adjusted for Hyperion data. The PRI (Equation 2) is a ratio of the difference between the blue absorption feature $(0.531 \mu \mathrm{m})$ and the green reflectance peak $(0.57 \mu \mathrm{m})$ and can be correlated with light efficiency in photosynthesis (GAMON, SERRANO and SURFUS, 1997).

$$
P R I=\frac{R_{0,531}-R_{0,57}}{R_{0,531}+R_{0,57}}
$$

However, PRI needs a rescheduling of its values to avoid negative data being called sPRI (Equation 3). Rescheduling to positive values is required to normalize vegetation "green" data. SPRI is obtained through PRI by adding one unit and dividing the result by two.

$$
s P R I=\frac{(P R I+1)}{2}
$$

The $\mathrm{CO}_{2}$ flux index is determined by multiplying the NDVI and sPRI information planes in the Band Math module.

\section{RESULTS AND DISCUSSION}

Aiming to find carbon sinks through the territory of Distrito Federal, it was applied both indexes - ICO2 and CO2flux along the proposed transect, investigating the dynamics related to the presence and absorption of $\mathrm{CO} 2$ through the landscape, in order to identify possible carbon sinks. As it follows, first was applied the ICO2 index and then the $\mathrm{CO} 2$ flux index, using ENVI ${ }^{\circledR}$ software, version 5.1, and its band math module. The next step was the correlation between the indexes above and validation of the carbon sinks that had been found by both methods.

It is important to note that the two indexes were previously validated by micrometeorological towers of the LBA project in the Amazon forest, in the contexts of primary forest, secondary forest, pasture and transition to cerrado (Silva and Baptista, 2015a; 2015b).

\subsection{Identification of carbon sinks through the use of the $\mathrm{ICO}_{2}$ index}

As expected, along the transect, it's possible to identify variations in the concentration of $\mathrm{CO}_{2}$ in the air column over the territory, according image 5 . Other important information is that it changes according to different kinds of land use and occupation.

As the Hyperion scene presents a contact between a conservation unit, the Brasilia National Park (PARNA Brasilia) and several urban centres of the Federal District, we sought to identify a recurring phenomenon in cities: the urban $\mathrm{CO}_{2}$ domes. These domes represent the high concentration of atmospheric $\mathrm{CO}_{2}$ in the air columns adjacent to urban targets (BAPTISTA, 2004). Two easily identifiable levels are observed in the study transect, the lower level corresponding to the National Park and the upper level associated to urban areas.

Another significant finding perceived by the study is that the concentration of carbon dioxide drops every time the transect crosses a vegetable area, even in urban targets, sometimes with similar behaviour of the forested areas in the National Park. It suggests that the presence of arboreal vegetation can be related to low levels of $\mathrm{CO}_{2}$ in the air column.

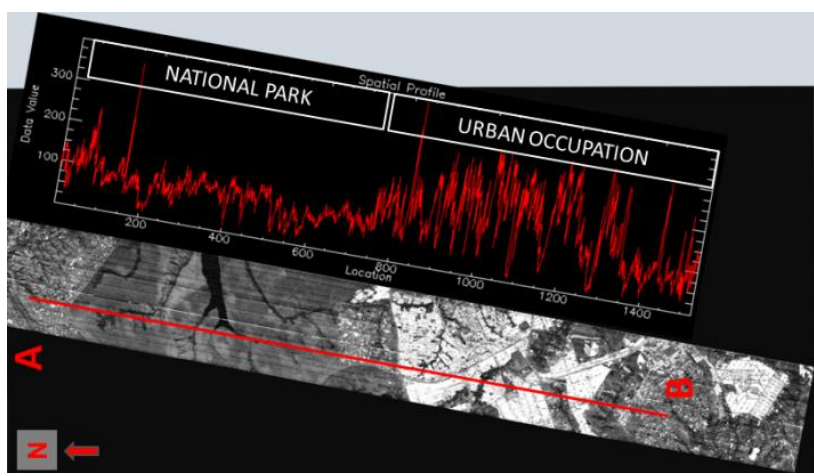

Image $5 . \mathrm{ICO}_{2}$ index applied along the $\mathrm{A}-\mathrm{B}$ transect

As it seems, the $\mathrm{ICO}_{2}$ index is able to seek variations of $\mathrm{CO}_{2}$ in the atmospheric air column, helping to identify areas with carbon sink action.

But what would be the carbon sequestration vegetation performance in the same area? Does it complement the findings of the concentration of carbon dioxide in the air column? To clear this relationship, the present study applied the $\mathrm{CO}_{2}$ flux index, related with the photosynthetic efficacy of the vegetation.

\subsection{Identification of carbon sinks through the use of the $\mathrm{CO}_{2}$ flux index}

Accordingly, with the findings in $\mathrm{ICO}_{2}$ index study, the photosynthetic activity, showed by the use $\mathrm{CO}_{2}$ flux index, over the National Park was significantly much more expressive than over the areas with urban occupations (image 6).

It corroborates with the urban $\mathrm{CO}_{2}$ domes phenomenon identified when $\mathrm{ICO}_{2}$ index was applied along the study transect. But, in spite of a significant drop in carbon sequestration in areas with urban occupation, it is possible to identify clusters of vegetation (probably arboreal) into urban sites, showing similar performance as forested parts in the National Park. It offers possible evidences of areas with a 
significant carbon sink behaviour intertwined with urban tissues.

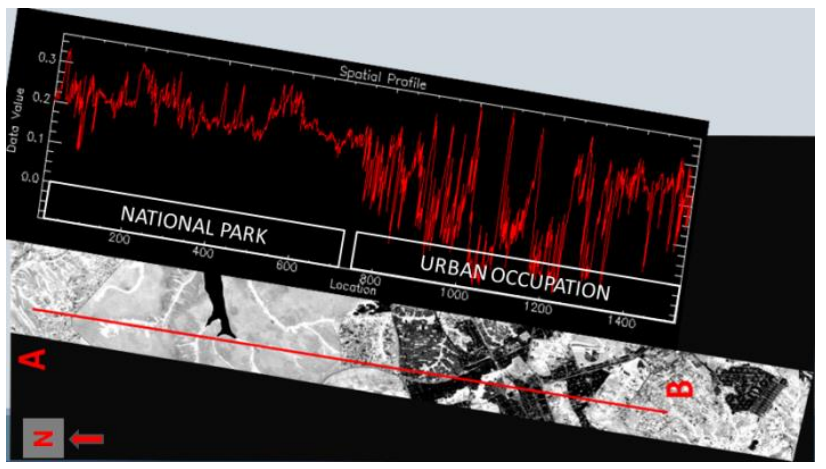

Image 6. $\mathrm{CO}_{2}$ flux index applied along the $\mathrm{A}-\mathrm{B}$ transect

The photosynthetic activity demonstrated with the application of the $\mathrm{CO}_{2}$ flux index could be related to the performance of the vegetation in the provision of support ecosystem services, especially primary production. These are necessary services to foster the welfare provided by the other categories (regulation, provision and culture).

However, to prove the relationship of both indexes, $\mathrm{ICO}_{2}$ and $\mathrm{CO}_{2}$ flux, with the provision of support ecosystem services, they must be correlated: the carbon sequestration pointed by $\mathrm{CO}_{2}$ flux should show a significant drop in the atmospheric $\mathrm{CO}_{2}$ in the air column, configuring a carbon sink.

So then is presented a correlation study between the indexes above in order to verify the validation of the carbon sinks that have been found by both methods.

\subsection{Correlation study between $\mathrm{ICO}_{2}$ and $\mathrm{CO}_{2} f l u x$}

According to graph 1, it can be noted, as previously mentioned, that the $\mathrm{CO}_{2}$ flux transect presents the opposite behaviours to the $\mathrm{ICO}_{2}$ transect. This confirms that areas with higher forest density, such as riparian forests, have high carbon sequestration efficiency values and low atmospheric $\mathrm{CO}_{2}$ contents. These parameters are inversely proportional because the higher the sequestration, the less atmospheric $\mathrm{CO}_{2}$ will exist in the column above the target.

Co2flux x ICO2

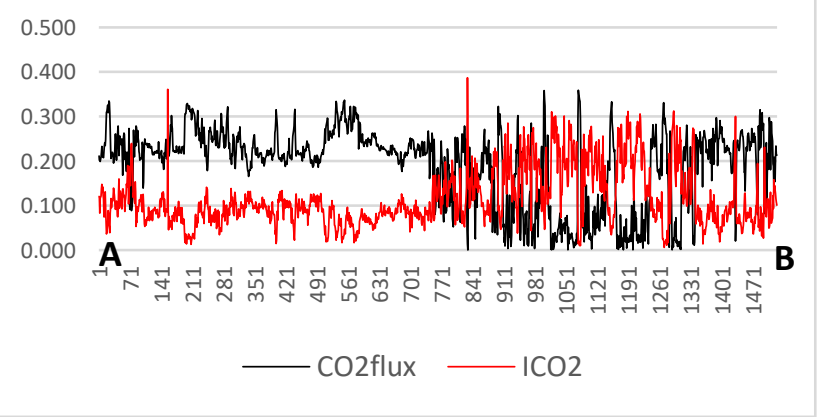

Graph 1. Comparison chart of the variations between the $\mathrm{ICO}_{2}$ and $\mathrm{CO}_{2}$ flux indexes applied along transect A-B
This fact was confirmed by the linear regression analysis between the results describing negative functions and high determination coefficient $(0,785)$, as presented in graph 2 .

This relationship between the indexes, prove that they can be used to identify and study carbon sink clusters in the territory. It could instrumentalize several researches, specifically the ones related with the behaviour and configuration of carbon sinks intertwined with urban tissues, or with some relationship between them, that could provide support to ecosystem services or enhance human welfare.

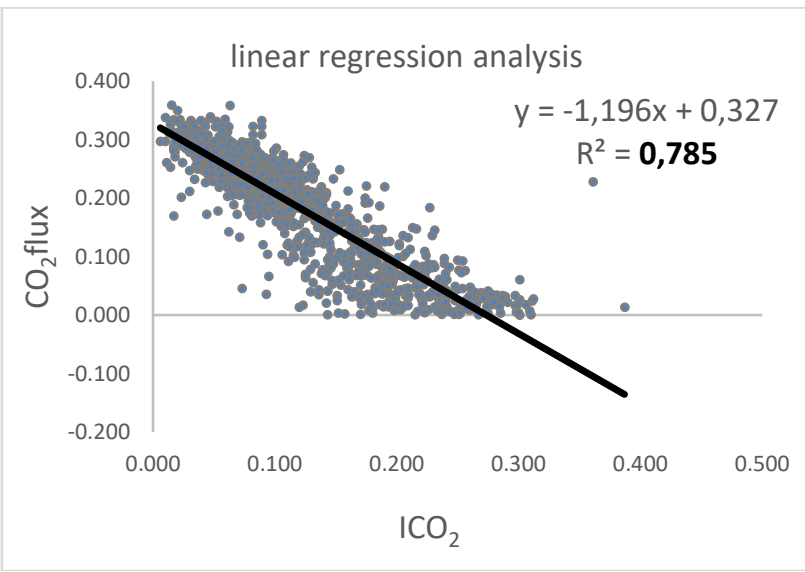

Graph 2. linear regression analysis between the application results of the $\mathrm{ICO}_{2}$ and $\mathrm{CO}_{2}$ flux indexes along transect A-B

\section{CONCLUSIONS}

Both indexes $\left(\mathrm{ICO}_{2}\right.$ and $\mathrm{CO}_{2}$ flux) have been shown to be capable of identifying carbon sinks in the territory. They, thus, provide evidences for investigating aspects related to vegetation performance in the provision of support ecosystem services in the landscape.

So hyperspectral images can be used with significant potential for territorial landscape planning based in the provision of ecosystem services. The use of $\mathrm{ICO}_{2}$ and $\mathrm{CO}_{2}$ flux appears to configure assertive carbon sink identification tools able to underpin guidelines for landscape planning based on the promotion and protection of support ecosystem services as well as the other categories, needed for human well-being (regulation, provision and culture).

It should also be emphasized the gains when disciplinary fields linked to remote sensing are integrated with the analysis of landscape performances in the provision of ecosystem services according to the Millennium Ecosystem Assessment Board (MEA, 2005).

Further studies should be encouraged to better understand the spectral relationship with the elements of the carbon cycle, in order to significantly improve the correlation between photosynthesis absorption and atmospheric $\mathrm{CO}_{2}$ contents, in order to deepen the perception of landscape attributes that could qualify this relationship and foster ecosystem services along the territory. 


\section{ACKNOWLEDGEMENTS}

We gratefully thank the Support Research Foundation of Distrito Federal - FAP/DF for the support to the project 0193.001373/2016 coordinated by professor Gustavo Macedo de Mello Baptista.

\section{REFERENCES}

Baptista, G. M. M., 2004. Mapeamento do seqüestro de carbono e de domos urbanos de $\mathrm{CO}_{2}$ em ambientes tropicais, por meio de sensoriamento remoto hiperespectral. Geografia 29(2), 189202.

Baptista, G. M. M., 2019. Sensoriamento remote hiperespectral. Editora Interciência, Rio de Janeiro.

Bélanger, P., 2017. Ladscape as infrastructure. Routledge, New York.

Bonam, G., 2008. Ecological climatology: concepts and applications. Cambridge. University Press, Cambridge.

Galvão, L. S.; Formaggio, A. R.; Tisot, D. A. Discriminação de variedades de cana-de-açúcar com dados hiperespectrais do sensor Hyperion/EO-1, 2005.. Revista Brasileira de Cartografia, 57(1) 7-14.

Gamon, J. A.; Serrano, L.; Surfus, J.S., 1997. The photochemical reflectance index: an optical indicator of photosynthetic radiation use efficiency across species, functional types, and nutrient levels. Oecologica, 112, 492-501.

Gao, B.C.; Goetz, A.F.H. Derivation of scaled surface reflectances from AVIRIS data, 1993. Remote Sensing of Environment. 44, 165-178.

Hobbs, R.J., 2007. Setting effective and realistic restoration goals: key directions for research. Restoration Ecology, 15, 354357.

Instituto Brasileiro de Geografia e Estatística - IBGE, 2019. Distrito Federal: História \& Fotos. cidades.ibge.gov.br /brasil/df/ historico (30 october 2019)

Millennium Ecosystem Assessment Board - MEA, 2005. Ecosystems and Human Well-being: A Framework for Assessment, Island Press, London.

Rahman, A. F.; Gamon, J. A.; Fuentes, D. A.; Roberts, D. A.; Prentiss, D., 2001. Modeling spatially distributed ecosystem flux of boreal forest using hyperspectral indices from AVIRIS imagery. Journal of Geophysical Research, 106(D24), p. 33.579-33.591.

Schramm, V. F.; Vibrans, A. C. Uso de imagens hiperespectrais (EO-1 Hyperion) para detalhamento da detecção das formações florestais na bacia do Itajaí, 2007. Dynamics Revista TecnoCientífica, 13(1), 59-69.

Silva, S. C. P, Baptista, G. M. M., 2015a. Análises espectrais da vegetação com dados hyperion e sua relação com a concentração e o fluxo de $\mathrm{CO}_{2}$ em diferentes ambientes na amazônia brasileira. Boletim de Ciências Geodésicas 21(2), 354-370.
Silva, S. C. P, Baptista, G. M. M., 2015b. Modelagens de sequestro florestal de carbono e dos conteúdos de $\mathrm{CO}_{2}$ atmosférico com dados hyperion em diferentes ambientes na amazônia brasileira. revista brasileira de cartografia (online) , (67), 1509-1521. 